\title{
A PRODUÇÃO DE QUEIJO COLONIAL ARTESANAL NO MUNICÍPIO DE SEARA, ESTADO DE SANTA CATARINA, FRENTE À LEGISLAÇÃO BRASILEIRA
}

\section{The production of Artisanal Colonial-type Cheese from Seara city, Santa Catarina state, with regard to Brazilian regulation}

\author{
Michelle de Medeiros Carvalho ${ }^{1,2 *}$, Juliano De Dea Lindner ${ }^{l}$, \\ Luciana Oliveira Fariña ${ }^{2}$
}

\begin{abstract}
RESUMO
O objetivo deste trabalho foi investigar a situação da produção do queijo Colonial artesanal (QCA), um produto típico da região sul do Brasil, produzido e comercializado no município de Seara, oeste do Estado de Santa Catarina, sob o ponto de vista da adequação das condições de trabalho perante a Instrução Normativa n 30 de 2013 do Ministério da Agricultura, Pecuária e Abastecimento, legislação vigente no Brasil que regulamenta o uso de leite cru para a fabricação de queijos com tempos de maturação inferiores a 60 dias. Para a realização do trabalho foram entrevistados 12 produtores, aplicando uma pesquisa qualitativa a campo para o diagnóstico situacional, utilizando como instrumento um formulário semi-estruturado. Os resultados obtidos indicaram que a situação da produção do QCA na área investigada não estava adequada no que diz respeito à legislação vigente, pois os produtores não têm acesso às condições necessárias para realizar análises (do leite, água e queijo), garantir a qualidade dos produtos com implantação das Boas Práticas de Ordenha e Fabricação ou certificar a propriedade como livre de zoonoses, como estabelecido pela Normativa.
\end{abstract}

Palavras-chave: leite cru; IN 30; queijo artesanal; boas práticas de fabricação.

1 Universidade Federal de Santa Catarina, Programa de Pós Graduação em Ciência dos Alimentos, Rodovia Admar Gonzaga, 1346, Itacorubi, 88034-001, Florianópolis, SC, Brasil. E-mail: michelle@leitecon. com.br

2 Universidade Estadual do Oeste do Paraná, Programa de Pós Graduação em Desenvolvimento Rural Sustentável, Marechal Cândido Rondon, PR, Brasil.

* Autor para correspondência. 


\begin{abstract}
The aim of this study was to investigate the current situation of 12 farms from Seara city, located in the west of the state of Santa Catarina that were producing and selling Artisanal Colonial-Type Cheese informally. A semistructured questionnaire was used to analyze the difficulties faced by these farmers in complying with current Brazilianlegislation for the production of artisanal raw milk cheese ripened less than 60 days. (Instrução Normativa 30/2013/ Ministério da Agricultura Pecuária e Abastecimento). The results indicated that, in the area investigated, the method of production of this cheese was not adequate in relation to the requirements ofcurrent legislation. The producers do not have access to the necessary resources to be able to properly analyze milk, water and cheese, to guarantee the quality of products through the implementation of Good Manufacturing and Milking Practices, nor are they able to certify the property as free of zoonosis, as required by the regulation.
\end{abstract}

Keywords: raw milk; IN 30; artisanal cheese; good manufacturing practices.

\section{INTRODUÇ̃̃O}

O queijo artesanal produzido no Brasil é tradicionalmente elaborado a partir de leite cru (SOUZA et al., 2003; MACHADO et al., 2004; FACHINETTO; SOUZA, 2010; MENEZES, 2011), porém a legislação vigente estabelece, em nome da segurança dos alimentos, a obrigatoriedade da pasteurização do leite utilizado na elaboração de queijos que possuam um período de maturação inferior a 60 dias (BRASIL, 1996), além de uma série de outras exigências com relação à estrutura física do local de fabricação do queijo (BRASIL, 1952).

Diante da evolução das cadeias de fabricação de produtos artesanais e da necessidade da liberação da fabricação do queijo artesanal produzido a partir de leite cru com período de maturação inferior a 60 dias, o Ministério da Agricultura, Pecuária e Abastecimento (MAPA) publicou a Instrução Normativa $n^{\circ} 30$ de 2013 (IN30/2013), que passou a autorizar a fabricação de queijos com leite cru em um período de maturação inferior ao anteriormente estabelecido, desde que alguns requisitos preestabelecidos sejam atendidos (BRASIL, 2013).
A IN 30/2013, para atender os produtores de queijo de leite cru brasileiros, estabeleceu os seguintes requisitos dispostos na Tabela 1.

Dados do último censo agropecuário indicam que a produção de queijos da agroindústria rural no Sul do Brasil envolviam cerca de 30.783 estabelecimentos rurais, sendo 5.838 no Estado de Santa Catarina. A produção total é de 14.344 toneladas ao ano, sendo o Estado de Santa Catarina responsável pela produção de 2.956 toneladas. Dividindo esta produção pelo número de produtores, chegamos a uma média de produção diária menor que $2 \mathrm{~kg}$ de queijo por dia, indicando uma produção de escala artesanal típica da agricultura familiar desta região (IBGE, 2006).

Há indicações de que, nos estados do Sul do país, a maioria dos queijos artesanais produzidos se tratem do Queijo Colonial, que é parte de um conjunto de produtos tradicionalmente processados nos estabelecimentos agrícolas pelos agricultores - os "colonos", descendentes de imigrantes europeus (CARVALHO, 2015). Para a comercialização desses produtos é necessário que esses estabelecimentos se formalizem perante os órgãos governamentais, o que implica no 
atendimento dos padrões higiênico-sanitários para a produção de alimentos (GAZOLLA; SCHNEIDER, 2015).

Diante desse cenário, o presente trabalho teve como objetivo investigar a situação de produção do Queijo Colonial Artesanal (QCA), um produto típico dos Estados da região sul do país, produzido a partir de leite cru e comercializado em Seara, município localizado no oeste do Estado de Santa Catarina. O enfoque do trabalho foi a adequação do QCA investigado no que se refere à IN 30/2013 e as potenciais razões da permanência ou não na informalidade comercial desses produtores.

\section{MATERIAL E MÉTODOS}

Este trabalho foi realizado com 12 pro- dutores informais de QCA no município de Seara, oeste do Estado de Santa Catarina, região sul do Brasil. O intermédio de contato com os produtores foi através de uma cooperativa a qual os mesmos eram associados.

De acordo com dados da cooperativa, o município é composto por 1200 propriedades rurais da agricultura familiar, onde 600 propriedades eram vinculadas à cooperativa. Dessas, 500 eram produtoras de leite e 371 produziam queijo. Das propriedades produtoras de queijo, 71 comercializavam o produto, sendo apenas uma propriedade com a atividade formalizada, a única que produzia queijo a partir de leite pasteurizado. Os produtores foram escolhidos mediante sorteio com um número sorteado acima do necessário devido a situação de informalidade da atividade, o que poderia gerar alguma

Tabela 1 - Requisitos estabelecidos pela IN 30/2013 para produção de queijos produzidos a partir de leite cru com maturação inferior a 60 dias para a comercialização em todo território nacional

Estudos técnico-científicos de comprovação da inocuidade do queijo;

Avaliação e redução do período de maturação realizados pelos órgãos de inspeção municipal ou estadual vinculados ao Sistema Brasileiro de Inspeção de Produtos de Origem Animal (SISBI/POA);

Produção restrita às queijarias situadas em propriedades de regiões com identidade geográfica ou tradicionalmente reconhecidas e livre ou controlada (por até três anos) de brucelose e tuberculose;

Descrição e implantação de Programa de Controle de Mastite clínica e subclínica, incluindo análise do leite em laboratório da Rede Brasileira da Qualidade do Leite (RBQL) para composição centesimal, Contagem de Células Somáticas (CCS) e Contagem Bacteriana Total (CBT);

Descrição e implantação de Programa de Boas Práticas de Ordenha e de Fabricação, incluindo o controle dos operadores, controle de pragas e transporte adequado do produto até o entreposto;

Cloração e controle de potabilidade da água utilizada nas atividades.

Fonte: BRASIL, 2004; BRASIL, 2006; BRASIL, 2013. 
rejeição da participação no trabalho, o que de fato ocorreu em três propriedades.

As propriedades rurais foram visitadas a fim de verificar os locais de ordenha, fabricação do queijo e obtenção da água empregada nas fases da obtenção do leite e produção. As visitas ocorreram no mês de maio de 2014.

Para o diagnóstico situacional, foi executada uma pesquisa qualitativa utilizando como instrumento um formulário semiestruturado com critérios estabelecidos por Carvalho (2015), com os dados a seguir: 1) Dados da propriedade, 2) Dados da Produção, 3) Dados da ordenha, 4) Sanidade animal, 5) Capacitação, 6) Qualidade do leite, 7) Controle da água de abastecimento, 8) Fabricação do queijo; e 9) Comercialização. Os resultados foram avaliados por meio de estatística descritiva. Os dados foram tabulados de acordo com as adequações e não adequações das condições observadas em cada propriedade, frente às exigências estabelecidas pela legislação atual (BRASIL, 2013; BRASIL, 2015).

\section{RESULTADOS E DISCUSSÃO}

As propriedades pesquisadas encontraram-se dentro do perfil apontado pelo último censo agropecuário no que se refere à produção de queijos em estabelecimentos rurais da agricultura familiar. Eram de pequeno porte e com volume de produção diário de queijo não elevado. Os queijos eram produzidos, em sua maioria, nas residências dos produtores rurais e $100 \%$ eram elaborados a partir de leite cru (Tabela 2).

Os produtores rurais envolvidos neste trabalho desconheciam, com precisão, sobre as exigências da legislação e, apesar de todos terem acesso ao crédito financeiro, as razões

Tabela 2 - Características das 12 propriedades verificadas

\begin{tabular}{lc}
\hline \multicolumn{1}{c}{ Característica } & Frequência de ocorrência \\
\hline Tamanho da propriedade & $\begin{array}{c}\text { Entre } 2,5 \text { e } 29,3 \text { ha } \\
\text { (média: } 13,9 \text { Ha) }\end{array}$ \\
Volume diário de leite & $\begin{array}{c}\text { Entre } 15 \text { e } 280 \mathrm{~L} \\
\text { (média: } 95 \mathrm{~L} / \mathrm{dia})\end{array}$ \\
Número de ordenhas diárias & 2 \\
Ordenha mecânica & $75,0 \%$ \\
Ordenha manual & $25,0 \%$ \\
Produção de queijo com leite cru & $100 \%$ \\
Possui local específico para fabricação de queijo & $16,6 \%$ \\
Propriedade controlada ou livre de brucelose e tuberculose & $0 \%$ \\
Capacitação em Boas Práticas de Ordenha e Manejo & $100 \%$ \\
Capacitação em Boas Práticas de Fabricação de alimentos & $8,3 \%$ \\
Propriedades que realizavam o tratamento da água com cloro & $0 \%$ \\
Produtores treinados no controle da potabilidade da água & $0 \%$ \\
\hline
\end{tabular}


que os impediam de construir ou melhorar o local apropriado para a fabricação dos queijos e se manterem formalizados encontram-se dispostos na Tabela 3 .

As respostas na Tabela 3 evidenciam as dificuldades colocadas pela legislação existente, assim como a importância de uma legislação específica para alimentos produzidos em pequena escala pela agricultura familiar com diretrizes que atendam este tipo de produção, somado a políticas públicas de incentivo fiscal e tributários que desoneram os custos produtivos.

Apesar da criação da IN 30/2013, pequenos estabelecimentos, como os pesquisados neste trabalho, possuem dificuldades para se formalizar, uma vez que eles devem seguir a mesma legislação estabelecida para indústrias de médio e grande porte no que se refere às exigências estruturais e tributárias. Este fato é também apontado por RIES et al. (2012).

Os produtores demonstraram preferência pela produção de queijo em detrimento à comercialização do leite fluido in natura; entre eles, 50,0\% além de produzirem o QCA, também comercializavam o leite para indústrias da região que possuíam inspeção estadual ou federal.

Em virtude das dificuldades de acesso, em algumas propriedades $(25 \%)$ a coleta do leite era realizada pelas indústrias de laticínios a cada quatro dias, o que justificaria a produção do queijo pelos produtores como uma maneira de melhor aproveitar a matériaprima produzida na propriedade, agregando maior valor a cadeia produtiva. Com maior

Tabela 3 - Razões que dificultavam a construção ou melhoria / adequação de um local específico para fabricação de queijos

\section{Característica}

Alto custo com taxas e impostos
Frequência de ocorrência

Investir e não obter registro de inspeção, por não existir uma norma clara e específica sobre a estrutura necessária $50,0 \%$ para uma queijaria deste porte

Obrigatoriedade de pasteurização do leite para fabricação do queijo

Burocracia para a formalização com documentações que não sabiam como providenciar e atender

Proibição de uso de materiais tradicionais que contribuem para uma boa qualidade sensorial do queijo, como a madeira

Receio de mudar a forma tradicional de fazer o queijo para atender a fiscalização

Ausência de mão de obra para investir no possível aumento da produção

Necessidade de contratação de responsável técnico

Exigências de aquisição de câmaras frias para a maturação do queijo 
agregação de valor do alimento produzido, o produtor passaria a ter uma maior autonomia financeira, colaborando com sua permanência no campo e melhoria na sua qualidade de vida.

Ao mesmo tempo, alimentos com potencial de maior qualidade estariam disponíveis para o consumidor já que o leite ordenhado seria utilizado na fabricação do queijo, na maioria das vezes, imediatamente após a ordenha, diferentemente dos queijos produzidos pelas indústrias de laticínios que coletam o leite nas propriedades.

Nenhuma propriedade era controlada ou certificada como livre de brucelose e tuberculose (Tabela 2), conforme estabelecido pela legislação vigente para a fabricação de queijo a partir de leite cru (BRASIL, 2013). O controle dessas doenças não era realizado pelos produtores devido aos altos custos com as análises, além da dificuldade operacional dos laboratórios, com filas de espera demasiadamente longas para coleta e análise no município onde as propriedades estavam localizadas. O controle da brucelose e tuberculose é extremamente importante para a segurança dos alimentos, pois a produção de queijos a partir de leite cru pode veicular e transmitir essas doenças para o consumidor, representando um grande risco à saúde pública (DINIZ, 2013; FARIA et al., 2014).

Quanto ao controle de mastite e às Boas Práticas de Ordenha e Fabricação, não havia programa descrito e implantado em nenhuma das propriedades. Além de não existirem esses programas de qualidade implementados, em $25 \%$ das propriedades não haviam pontos de água para realização dos processos de higienização durante a ordenha e a água era transportada em baldes.

O controle de mastite só era realizado pelos produtores que forneciam leite para laticínios com inspeção federal $(33,2 \%)$, os quais recebiam tais orientações dessas empresas privadas, e, também, somente estes produtores realizavam análise do leite em laboratório da Rede Brasileira da Qualidade do Leite (RBQL).

Os produtores que forneciam leite para laticínios com inspeção estadual (16,6\%), não realizavam as análises do leite com a frequência estabelecida pela legislação e não recebiam orientações sobre o controle de mastite. Os demais produtores, que não comercializavam o leite para fábricas de laticínios, desconheciam as análises do leite previstas na legislação (BRASIL, 2011).

Apesar de todos os produtores já terem realizado algum tipo de curso referente às Boas Práticas de Ordenha, apenas 8,3\% realizou curso de Boas Práticas de Fabricação de Queijos (Tabela 2). Araújo et al. (2011) constataram que $100 \%$ dos produtores de Queijo Minas Artesanal Araxá tinham curso de capacitação em Boas Práticas de Ordenha e Fabricação de Queijos, apesar de apenas 29,0\% possuírem credenciamento de adequação das Boas Práticas junto ao órgão fiscalizador. A adoção de Boas Práticas de Fabricação é um requisito essencial para a produção de um alimento seguro (DINIZ, 2013).

Em todas as propriedades avaliadas, gatos domesticados eram utilizados para o controle de pragas (roedores). Em estudo semelhante, Pinto et al. (2009) constataram a presença de animais domésticos em $97 \%$ das propriedades avaliadas na região do Serro, em Minas Gerais.

As águas utilizadas no processo de fabricação dos queijos eram oriundas das próprias propriedades, sendo captadas em poços artesianos e em fontes superficiais (Tabela 2). As águas coletadas eram armazenadas em reservatórios de água construídos com material de fibra, e os produtores não possuíam treinamento quanto aos procedimentos e as periodicidades de higienização adequadas desses reservatórios de água.

Nenhuma propriedade realizava a cloração da água que era utilizada na sanitização 
dos equipamentos envolvidos na ordenha e fabricação do queijo (Tabela 2). Todos os produtores demonstraram interesse na cloração, caso a água da propriedade apresentasse problema de contaminação. Se ela não apresentasse problemas de contaminação de origem microbiológica, os produtores preferiam não utilizar tratamento químico nessa água. A preocupação com a qualidade da água era evidente, pois a água utilizada no processo de fabricação do queijo era a mesma do consumo familiar. Em estudos similares realizados no estado de Minas Gerais, produtores de queijos artesanais apresentaram certa resistência em utilizar o cloro como sanificante, por acreditarem que este produto interferiria na caracterização do produto final (ARAUJO, 2004; PINTO et al, 2009).

O tratamento de cloração da água é importante para a segurança e qualidade, especialmente quando existe alguma possibilidade de contaminação em sua origem de obtenção. O processo de cloração da água deve ser realizado e controlado de maneira adequada, para isso, é necessário que os produtores recebam treinamento para a dosagem correta do cloro, assim como a realização de análises de controle do teor de cloro livre, as quais podem ser feitas pelos próprios produtores diariamente na propriedade.

A comercialização dos queijos era realizada nas propriedades rurais ou o produto era entregue nas residências dos clientes, sendo produzidos por encomenda. Os produtores demonstraram grande receio nessa comercialização em razão dos riscos de apreensão do produto e da punição dos órgãos de fiscalização, o que resultaria em importante perda da renda familiar. No caso da produção do queijo Serrano artesanal, grande parte dos produtores não comercializava seus queijos devido ao risco da apreensão. A venda era realizada por atravessadores, que assumiam os riscos de terem a mercadoria apreendida (CRUZ, 2012).

\section{CONCLUSÕES}

A situação da produção do QCA da região investigada não está adequada em relação à legislação existente para fabricação de queijo a partir de leite cru. Os produtores demonstraram não ter condições de realizar, sem apoio, as análises do leite, da água e do queijo, a fim de poder garantir a qualidade e segurança dos produtos com descrição e aplicação das Boas Práticas, ou certificar a propriedade como livre de zoonoses.

Apesar da existência de uma legislação específica para fabricação de queijo de leite cru no Brasil, na região pesquisada permanecem as dificuldades de formalização desta atividade por não existir políticas públicas para orientação adequada destes produtores quanto às exigências normativas, pela ausência de uma legislação que atenda a produção artesanal da agricultura familiar do ponto de vista estrutural e tributário, assim como a falta de estudos suficientes voltados para certificar a qualidade e segurança dos produtos fabricados a partir de leite cru.

\section{AGRADECIMENTOS}

Agradecemos a Empresa de Pesquisa Agropecuária e Extensão Rural de Santa Catarina (EPAGRI / SC) dos municípios de Chapecó e Seara e da Cooperativa de Crédito Rural Seara (CREDISEARA) do município de Seara pelo apoio e suporte ao trabalho realizado. Agradecemos também a Rosangela Pezza Cintrão, Daniel Strongin e professora Célia Lúcia de Luces Fortes Ferreira pela leitura e contribuições.

\section{REFERÊNCIAS}

ARAUJO, R. A. B. M. Diagnóstico do queijo Minas artesanal da região de Araxá. 2004. 121 f. Dissertação (Mestrado em Ciência e 
Tecnologia de Alimentos) - Universidade Federal de Viçosa, Viçosa, 2004.

ARAUJO, L. P. P. et al. Perfil das unidades produtoras e diagnóstico do impacto ambiental na fabricação de queijo Minas artesanal da Serra da Canastra, MG. In: SEMINÁRIO DE INICIAÇÃO CIENTÍFICA E TECNOLÓGICA, 8., 2011, Belo Horizonte. Anais eletrônicos... Belo Horizonte: EPAMIG, 2011. Disponível em: < http:// www. epamig.br/index.php?option $=$ com docman\&task $=$ cat_view $\&$ gid $=150 \&$ limit $=$ 10\&limitstart $=40 \&$ order $=$ hits \&dir $=$ ASC $>$. Acesso em: 10 jan. 2016.

BRASIL. Decreto no 30691, de 29 de março de 1952. Aprova o novo Regulamento da Inspeção Industrial e Sanitária de Produtos de Origem Animal. Diário Oficial da República do Brasil, Brasília, 07 jul. 1952.

BRASIL. Ministério da Agricultura, Pecuária e Abastecimento. Portaria $n^{\circ} 146$, de 7 de março de 1996. Aprova os regulamentos técnicos de identidade e qualidade dos produtos lácteos. Diário Oficial da República do Brasil, Brasília, 11 mar. 1996. Seção 1, Página 3977.

BRASIL. Ministério da Agricultura, Pecuária e Abastecimento. Instrução Normativa $\mathrm{n}^{\mathrm{o}}$ 6, de 08 de janeiro de 2004. Aprova o Regulamento Técnico do Programa Nacional de Controle e Erradicação da Brucelose e Tuberculose Animal. Diário Oficial da República do Brasil, Brasília, 12 jan. 2004. Seção 1, p. 6-10.

BRASIL. Decreto $\mathrm{n}^{\circ} 5741$ de 30 de março de 2006. Regulamenta os arts. 27-A, 28-A e 29-A da Lei $n^{\circ} 8.171$, de 17 de janeiro de 1991, organiza o Sistema Unificado de Atenção à Sanidade Agropecuária, e dá outras providências. Diário Oficial da República do Brasil, Brasília, 31 mar. 2006. Seção 1, p. 82 .

BRASIL. Ministério da Agricultura, Pecuária e Abastecimento. Instrução Normativa $\mathrm{n}^{\circ}$ 62, de 29 de dezembro de 2011. Aprova o Regulamento Técnico de Produção, Identidade e Qualidade do Leite tipo A, o Regulamento Técnico de Identidade e Qualidade de Leite Cru Refrigerado, o Regulamento Técnico de Identidade e Qualidade de Leite Pasteurizado e o Regulamento Técnico da Coleta de Leite Cru Refrigerado e seu Transporte a Granel, em conformidade com os Anexos desta Instrução Normativa. Diário Oficial da República Federativa do Brasil, Brasília, 30 dez. 2011. Seção 1, p. 6.

BRASIL. Ministério da Agricultura, Pecuária e Abastecimento - MAPA. Instrução Normativa $n^{\circ} 30$, de 7 de agosto de 2013. Estabelece critérios adicionais para elaboração de Queijos Artesanais. Diário Oficial da República Federativa do Brasil, Brasília, 08 nov. 2013. Seção 1, p. 19.

BRASIL. Ministério da Agricultura, Pecuária e Abastecimento - MAPA. Instrução Normativa $n^{\circ} 16$, de 23 de junho de 2015. Estabelece, em todo o território nacional, as normas específicas de inspeção e a fiscalização sanitária de produtos de origem animal, referente às agroindústrias de pequeno porte. Diário Oficial da República Federativa do Brasil, Brasília, 24 jun. 2015.

CARVAlho, M. M. A Agroindústria Familiar Rural e a Produção de Queijos Artesanais no Município de Seara, Estado de Santa Catarina - Um Estudo de Caso. 2015. 42 f. Dissertação (Mestrado em Desenvolvimento Rural Sustentável) - Campus Marechal Cândido Rondon, Universidade Estadual do Oeste do Paraná, Marechal Cândido Rondon, 2015. 
CRUZ, F. T. Produtores, consumidores e valorização de produtos tradicionais: um estudo sobre qualidade de alimentos a partir do caso do Queijo Serrano dos Campos de Cima da Serra - RS. 2012. 292 f. Tese (Doutorado em Desenvolvimento Rural) Universidade Federal do Rio Grande do Sul, Porto Alegre, 2012.

DINIZ, M. F. S. Queijo Canastra: um estudo envolvendo aspectos culturais e parâmetros de inocuidade do alimento. 2013. $159 \mathrm{f}$. Dissertação (Mestrado em Ciência e Tecnologia de Alimentos) - Escola Superior de Agricultura Luiz de Queiroz, Universidade de São Paulo, Piracicaba, 2013.

FARIA, A. C. S. et al. Short communication: viable Mycobacterium avium subspecies paratuberculosis in retail artisanal Coalho cheese from Northeastern Brazil. Journal of Dairy Science, v. 97, n. 7, p. 4111-4114, 2014.

FACHINETTO, D. B.; SOUZA, C. F. V. Avaliação da qualidade microbiológica de queijo colonial, produzido e comercializado por pequenos produtores no Vale do Taquari, RS. Higiene Alimentar, v. 24, n. 180/181, p. 64-67, 2010.

GAZOLLA, M.; SCHNEIDER, S. Conhecimentos, produção de novidades e transições sociotécnicas nas agroindústrias familiares.
Organizações Rurais \& Agroindustriais, v. 17, n. 2, p. 179-194, 2015.

IBGE - Instituto Brasileiro de Geografia e Estatística. Censo Agropecuário, 2006.

MACHADO, E. C. et al. Características físico-químicas e sensoriais do Queijo Minas Artesanal produzido na região do Serro, Minas Gerais. Ciência e Tecnologia Alimentar, v. 24, n. 4, p. 516-521, 2004.

MENEZES, S. S. M. Queijo de coalho: tradição cultural e estratégia de reprodução social na região Nordeste. Revista de Geografia (UFPE), v. 28, n. 1, p. 40-56, 2011.

PINTO, M. S. et al. Segurança alimentar do Queijo Minas Artesanal do Serro, Minas Gerais, em função da adoção de Boas Práticas de Fabricação. Pesquisa Agropecuária Tropical, v. 39, n. 4, p. 342-347, 2009.

RIES, J. E. et al. Projeto de qualificação e certificação do Queijo Serrano produzido nos Campos de Cima da Serra do Rio Grande do Sul. Agroecologia e Desenvolvimento Rural Sustentável, v. 5, n. 1, p. 10-19, 2012.

SOUZA, C. F. V. et al. Changes in the microbiological and physicochemical characteristics of Serrano cheese during manufacture and ripening. Brazilian Journal Microbiology, v. 34, n. 3, p. 206-266, 2003. 